\title{
\begin{tabular}{|l|l|l|l|l}
\hline $\mathrm{M}$ & $\mathrm{R}$ & $\mathrm{S}$ & Internet Journal of & Nitride Semiconductor Research \\
\hline
\end{tabular}
}

Volume 2, Article 27

\section{MOVPE Growth and Structural Characterization of $\mathrm{Al}_{x} \mathrm{Ga}_{1-x} \mathrm{~N}$}

\author{
S. Ruffenach-Clur, Olivier Briot, Bernard Gil, Roger-Louis Aulombard \\ Groupe d'Etude des Semiconducteurs, GES-CNRS
}

J. L. Rouviere

CEA/Grenoble, Département de Recherche Fondamentale sur la Matière Condensée/SP2M

This article was received on June 9, 1997 and accepted on September 12, 1997.

\begin{abstract}
The ternary alloy GaAIN has been grown by low pressure MOVPE (76 Torr) using triethylgallium, trimetylaluminum and ammonia as precursors. The alloy layers were grown on (0001) sapphire substrates using a low temperature AIN buffer. All layers were deposited at a growth temperature of $980^{\circ} \mathrm{C}$. Only the aluminum/gallium ratio in the gas phase was changed, keeping the total group III molar flow rate and V/III molar ratio constant.

The aluminum incorporation versus gas phase composition was determined experimentally, using energy dispersive analysis of X-rays (EDAX), and X-ray diffraction. We propose a model, taking into account kinetically limited mass transport of group III species in the gas phase, which describes well the data.
\end{abstract}

The structural quality of the layers was investigated using X-ray diffraction and TEM experiments.

A degradation of the materials quality is observed with increasing Al content. In this case, growth originate on the buffer grains facets resulting in a " two directional » growth. This phenomenon, being markedly enhanced when increasing the Al content will be detailed in this paper.

\section{Introduction}

The AIGaN alloy is a solid solution over the whole range of composition and has a direct band gap from 3.4 to $6.2 \mathrm{eV}$. Therefore, it is a promising material for devices application in the visible range when associated to InGaN [1] [2], and in the UV range for photodetectors [3]. To obtain high quality AIGaN for electronic application, it is necessary to study at first the growth mechanisms involved in the AIGaN growth. Therefore, we study the aluminum gallium nitride solid solution in the whole range of composition, varying the gas phase composition for $10 \%$ from one sample to another. This leads us to establish a model for the aluminum incorporation into the solid phase. We were very careful to keep all the growth parameters constant, even the total group III molar flow rate. We observed a decrease in the epilayer crystalline quality with increasing AI content as demonstrated by TEM, and X-Ray diffraction. Indeed, at high Al contents (above $50 \%$ aluminum), a second crystalline orientation appears resulting in a " two directional " growth induced by the buffer layer.

\section{Experimental}

The AIGaN epilayers were grown using triethylgallium, trimethylaluminum and ammonia by low pressure (76 Torr) MOVPE. The layers were deposited onto a $500 \AA$ AIN buffer layer grown at low temperature on a c-face sapphire substrate. We grew layers covering the whole range of AIGaN composition from GaN up to AIN. The data concerning the growth are tabulated (Table1). The organometallic bubbler temperatures were $19^{\circ} \mathrm{C}$ for the TMAI and $15.5^{\circ} \mathrm{C}$ for the TEGa. Before the growth, the substrates were cleaned in a hot $1 \mathrm{H}_{3} \mathrm{PO}_{4}: 3 \mathrm{H}_{2} \mathrm{SO}$ 4 mixture for 10 minutes and was nitrided for 10 minutes under $300 \mathrm{sccm}$ ammonia at 76 Torr. 
The Al composition was determined by energy dispersive analysis of X-ray (EDAX), making the proper corrections for atomic number, absorption and fluorescence. These results were in good agreement with the X-ray diffraction data, assuming that the $c$ lattice parameter of the alloy satisfies Vegard's law. Cross sections for TEM were prepared using the standard procedures: mechanical polishing and Argon ion milling. TEM observations were realized on a JEOL 4000 EX electron microscope.

\section{Results and Discussion}

First, we studied the aluminum incorporation in the solid phase during low pressure MOCVD growth. In the literature, observations are reported concerning high reactivity between TMAI and ammonia [4] leading to adducts formation [5]. We must point out that due to our reactor inlet design and to the reactor low pressure, adducts formation is negligible in our growth process. Therefore, making the assumptions that the growth mechanism is limited by mass-transport of group III elements through the gas phase [6] and that the solid composition will be determined by the relative $\mathrm{Al}$ and $\mathrm{Ga}$ fluxes reaching the interface by diffusion, we can write [7]:

$$
x=\frac{1}{\left(1+k\left(\frac{1}{x_{g}}-1\right)\right)}
$$

sratio between the gallium precursor diffusion coefficient $D_{G a}$ through the mixture of ammonia and hydrogen (used as carrier gas) and the aluminum one, $\mathrm{D}_{\mathrm{al}}$. To calculate the diffusion coefficients for the organometallic precursors in an ammonia/hydrogen gas mixture we first use the Wilke and Lee model [8], taking into account the diffusion process involved by the concentrations gradient corrected by a contribution due to the thermal gradient [9]. We found for $k$ the value 0.834 , which fits well the experimental data (Figure 1). The details of this model will be reported elsewhere.

To analyze the quality of our epilayers, we have performed X-ray diffraction measurements. These experiments evidence a decrease of the epilayers quality with increasing Al content (Figure 2). Moreover, it appears that above 50\% Al content, the growth becomes "two directional ". SEM indicate clearly a change in the surface morphologies which start smooth at low Al contents and sharply after $50 \% \mathrm{Al}$, become acicular with a clear six-fold symmetry [10] [11]. The reasons for these modifications will be given below, from the TEM results. Four $\mathrm{Al}_{\mathrm{x}} \mathrm{Ga}_{1-\mathrm{x}} \mathrm{N}$ samples with different $\mathrm{Al}$ compositions $(\mathrm{x}=0.16, \mathrm{x}=0.45, \mathrm{x}=0.55, \mathrm{x}=0.85)$ have been observed using Transmission Electron Microscopy. The two last samples greatly differ from the two first ones. The samples with a low Al concentration looks like traditional GaN layers. They are monocrystalline with a Ga polarity (ref. [12] [13] [14]) and contain a high density of dislocations (about $1010 / \mathrm{cm}^{2}$ ) and many nanopipes (ref. [15]). The samples with an Al content higher than 0.55 contain two kinds of textures: the

planes parallel to the initial (0001) sapphire surface plane can be the $(0001)$ plane or the pyramidal $\left\{\begin{array}{lll}10 & 1\end{array}\right\}$ planes. These two textures clearly appear in the diffraction pattern of Figure $3 \mathrm{~b}$. The angular width of these textures is about $\pm 4^{\circ}$. Due to the symmetry of the wurtzite material, the $\{10 \overline{1} \quad 1\}$ texture has six variants. These six variants can be characterized by the orientation of the $c$ and $a=[2 \overline{1} \overline{1} \quad 0]$ axis with respect to the texture of the (0001) AIN buffer layer which is defined by: $\mathrm{AIN}(0001)\left[\begin{array}{lll}2 \overline{1} \overline{1} & 0\end{array}\right] / \mathrm{Al}_{2} \mathrm{O}_{3}(0001)\left[\begin{array}{ll}10 \overline{1} & 0\end{array}\right]$. The six different orientations of the grains are:

$$
\begin{aligned}
& \operatorname{AIGaN}(0001)[2 \overline{1} \overline{1} \quad 0] / / \operatorname{AIN}(01 \overline{1} \quad 1)[2 \overline{1} \overline{1} \quad 0] \\
& \operatorname{AIGaN}(0001)[2 \overline{1} \overline{1} \quad 0] / / \operatorname{AIN}(0 \overline{1} \quad 11)[2 \overline{1} \overline{1} \quad 0]
\end{aligned}
$$

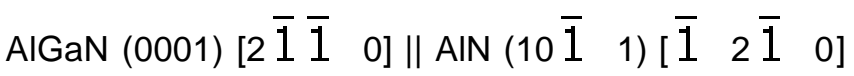




$$
\begin{aligned}
& \operatorname{AIGaN}(0001)[2 \overline{1} \overline{1} \quad 0] \| \operatorname{AIN}\left(\begin{array}{lll}
\overline{1} & 011
\end{array}\right)\left[\begin{array}{lll}
\overline{1} & 2 \overline{1} & 0
\end{array}\right]
\end{aligned}
$$

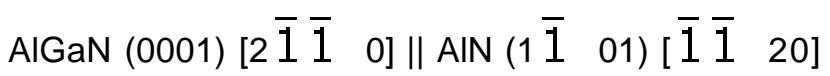

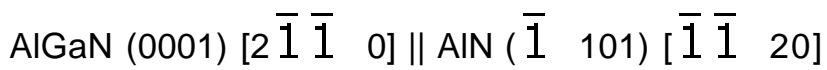

Two of these variants can be clearly seen on a HREM picture (Figure 3a) taken along the $a=\left[\begin{array}{lll}2 \overline{1} & 0\end{array}\right]$ direction. The four other variants cannot be resolved on this HREM image, but are present due to the symmetry of the crystal. It appears that at high Al concentration, the $\{10 \overline{1} 1\}$ is favored. Such a texture has already been reported in GaN layers grown on (0001) sapphire [16]. But in this case, the $\{10 \overline{1} 1\}$ textured grains were very small and appeared only in the buffer layer. In our case, HREM images reveal that the $\{10 \overline{1}$ 1 ) textures start growing at once on the AIN buffer layer (not on the sapphire surface) and that they propagate throughout the layer. These grains are responsible of the rough surfaces observed at high aluminum contents

[10]: $\{10 \overline{1} 1\}$ grains are higher than (0001) grains and forms grains elongated along the $\{2 \overline{1} \overline{1} \quad 0\}$ directions. For $x=0.85$, the average width of these grains is $75 \mathrm{~nm}$; their length cannot be determined on the TEM cross-section. Since the buffer texture is the same in all the samples, we have to correlate the fact that the $\{10$ $\overline{1} 1\}$ textures appear in the epilayers with the increasing aluminum content. At high Al content, $\{10 \overline{1} 1\}$ domains grow on the facets of the grains, which are present in the buffer layer. At low Al content, the buffer roughness is smoothened during GaN growth, due to the higher surface mobility of the $\mathrm{Ga}$ adatoms. This assumption was confirmed by the growth of AIN at temperatures increasing from $980^{\circ} \mathrm{C}$ up to $1080^{\circ} \mathrm{C}$ which demonstrates a clear increase in the crystalline quality with increasing growth temperature [10].

\section{Conclusion}

We have grown AIGaN in the whole range of composition using the same growth temperature for all layers. Considering that the growth mechanism is mass-transport limited and that the solid composition will be determined by the relative $\mathrm{Al}$ and Ga fluxes reaching the interface by diffusion, we have successfully modeled the aluminum incorporation from the gas phase to the solid AlGaN. Structural characterizations display an evolution in the surface morphologies which are sharply modified for more than 50\% aluminum. At high $\mathrm{Al}$ content, due to the Al low surface mobility, growth originates both on (0001) plans and on the buffer (10 $\overline{1}$ grains facets. In contrast, Ga adatoms high surface mobility prevent any influence of the buffer roughness during the growth. The correlation between surface morphologies and Al content lead us to assume that in order to grow high quality AIGaN epilayers it is necessary to optimize the growth temperature for each composition. This growth temperature is to be increased with increasing Al contents.

\section{Acknowledgments}

\section{This work has been supported by the DRET/DGA and by THOMSON-CSF-LCR.}

\section{References}

[1] Shuji Nakamura, Gerhard Fasol, The Blue Laser Diode - GaN based Light Emitters and Lasers (Springer-Verlag, Heidelberg, 1997).

[2] S. Nakamura, M. Senoh, S. Nagahama, N. Iwasa, T. Yamada, T. Matsushita, Y. Sugimoto, H. Kiyotu, Appl. Phys. Lett. 70, 868 (1997).

[3] D. Walker, X. Zhang, A. Saxler, P. Kung, J. Xu, M. Razeghi, Appl. Phys. Lett. 70, 949-951 (1997).

[4] C. H. Chen, H. Liu, D. Steigerwald, W. Imler, C. P. Kuo, M. G. Craford, M. Ludowise, S. Lester, J. Amano, J. Electron. Mater. 25, 1004 (1996).

[5] Y. Koide, H. Itoh, N. Sawaki, I. Akasaki, M. Hashimoto, J. Electrochem.Soc. 133, 1956 (1986). 
[6] M. A. Khan, R. A. Skogman, R. G. Schulze, M. Gershenzon, Appl. Phys. Lett. 43, 492 (1983).

[7] G. B. Stringfellow, Organometallic Vapor-Phase Epitaxy:Theory and Practice (Academic Press, New York, 1989).

[8] R.C. Reid, J.M. Prausnitz, B.E. Polling, The properties of gases and liquids (McGraw-Hill, New York, 1987) .

[9] W. L. Holstein, J. Electrochem. Soc. 135, 1788 (1988).

[10] S. Clur, O. Briot, J. L. Rouvière, A. Andenet, Y-M. Le Vaillant, B. Gil, R. L. Aulombard, J. F. Demangeot, J. Frandon, M. Renucci, unpublished (1997).

[11] M. Morita, N. Uesugi, S. Isogai, K. Tsubouchi, N. Mikoshiba, Jpn. J. Appl. Phys. 20, 17 (1981).

[12] J. L. Rouviere, M. Arlery, R. Niebuhr, K. H. Bachem, Olivier Briot, MRS Internet J. Nitride Semicond. Res. 1, 33 (1996).

[13] B Daudin, JL Rouviere, M Arlery, Appl. Phys. Lett. 69, 2480-2482 (1996).

[14] F.A. Ponce, D.P. Bour, W.T. Young, M. Saunders, J.W. Steeds, Appl. Phys. Lett. 69, 337-339 (1996).

[15] W Qian, M Skowronski, K Doverspike, LB Rowland, DK Gaskill, J. Cryst. Growth 151, 396 (1995).

[16] S. Christiansen, M. Albrecht, W. Dorsch, H. P. Strunk, C. Zanotti-Fregonara, G. Salviati, A. Pelzmann, M. Mayer, Markus Kamp, K. J. Ebeling, MRS Internet J. Nitride Semicond. Res. 1, 19 (1996).

\section{Table 1}

Growth conditions. $\mathrm{H}_{2}$ was used as carrier gas.

\begin{tabular}{|c|c|c|c|c|c|c|}
\hline $\begin{array}{l}\mathrm{A} \mathrm{l}_{\text {content in }} \\
\mathrm{Al}_{\mathrm{x}} \mathrm{Ga}_{1-\mathrm{x}^{\mathrm{N}}} \text { (\%) }\end{array}$ & $\begin{array}{l}\text { Al content } \\
\text { in gas ( }\left(\frac{0}{0}\right)\end{array}$ & $\begin{array}{l}\text { TEGa flow } \\
\text { rate } \\
(\mathrm{sccm})\end{array}$ & $\begin{array}{l}\text { TMAl flow } \\
\text { rate } \\
(\mathrm{sccm})\end{array}$ & $\begin{array}{l}\mathrm{NH}_{3} \text { flow } \\
\text { rate } \\
(\mathrm{sccm})\end{array}$ & $\begin{array}{l}\text { Growth } \\
\text { temperature } \\
\left({ }^{\circ} \mathrm{C}\right)\end{array}$ & $\begin{array}{l}\text { V/III } \\
\text { molar } \\
\text { ratio }\end{array}$ \\
\hline 0 & 0 & 89.18 & 0 & & & \\
\hline 16 & $\mid 10$ & 80.25 & 4.17 & & & \\
\hline 26 & 20 & 71.16 & 8.09 & & & \\
\hline 36 & 30 & 62.60 & 12.25 & & & \\
\hline 45 & 40 & 53.50 & 16.42 & 3750 & 980 & 10,000 \\
\hline 55 & 50 & 44.41 & 20.34 & & & \\
\hline 62 & 60 & 35.85 & 24.5 & & & \\
\hline 71 & 70 & 26.75 & 28.67 & & & \\
\hline 85 & 80 & 17.66 & 32.59 & & & \\
\hline 100 & 100 & 0 & 40.84 & & & \\
\hline
\end{tabular}




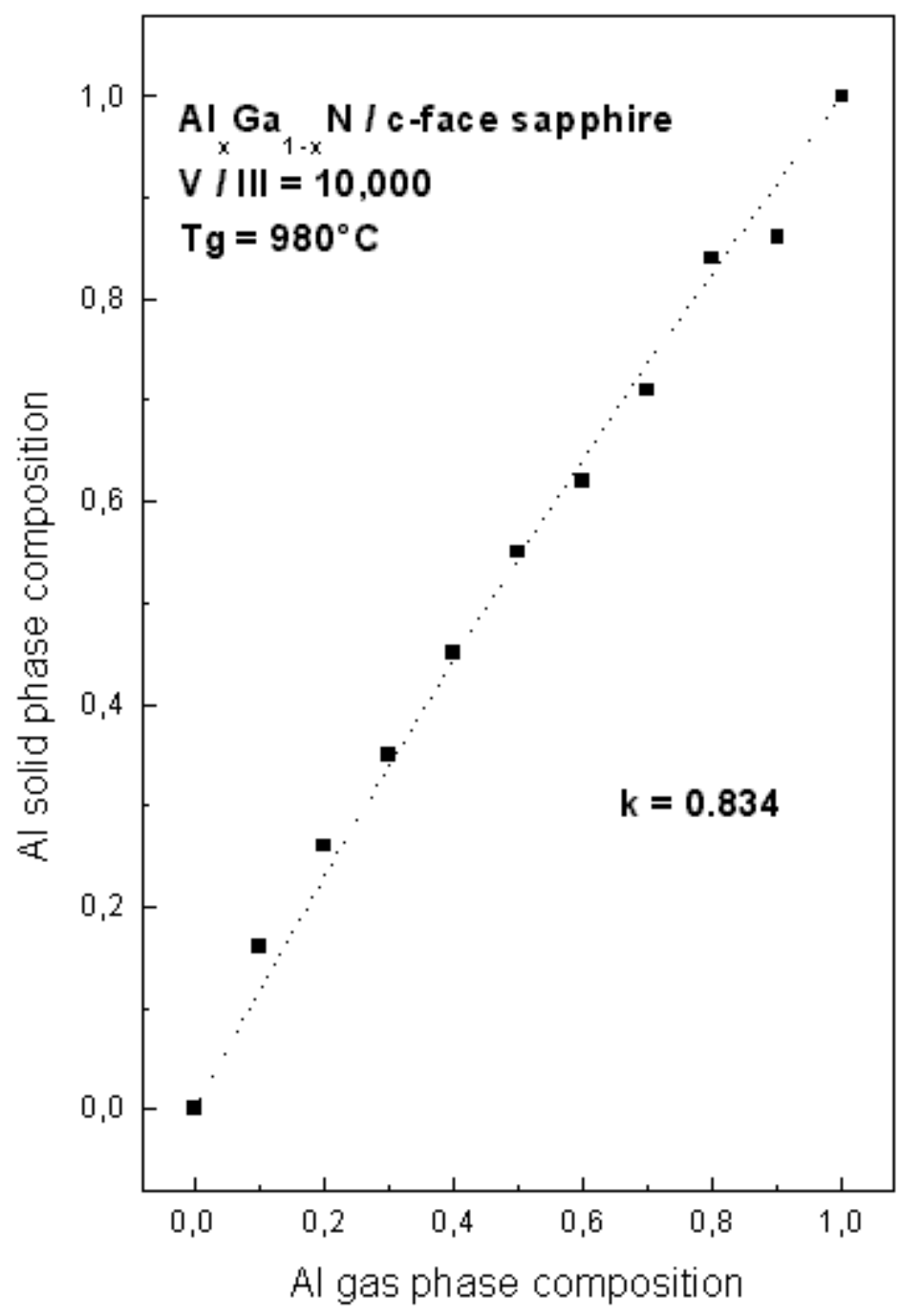

Figure 1. AIGaN solid phase composition versus gas phase composition. The squares represent the experimental data fitted by our model (dashed line). 


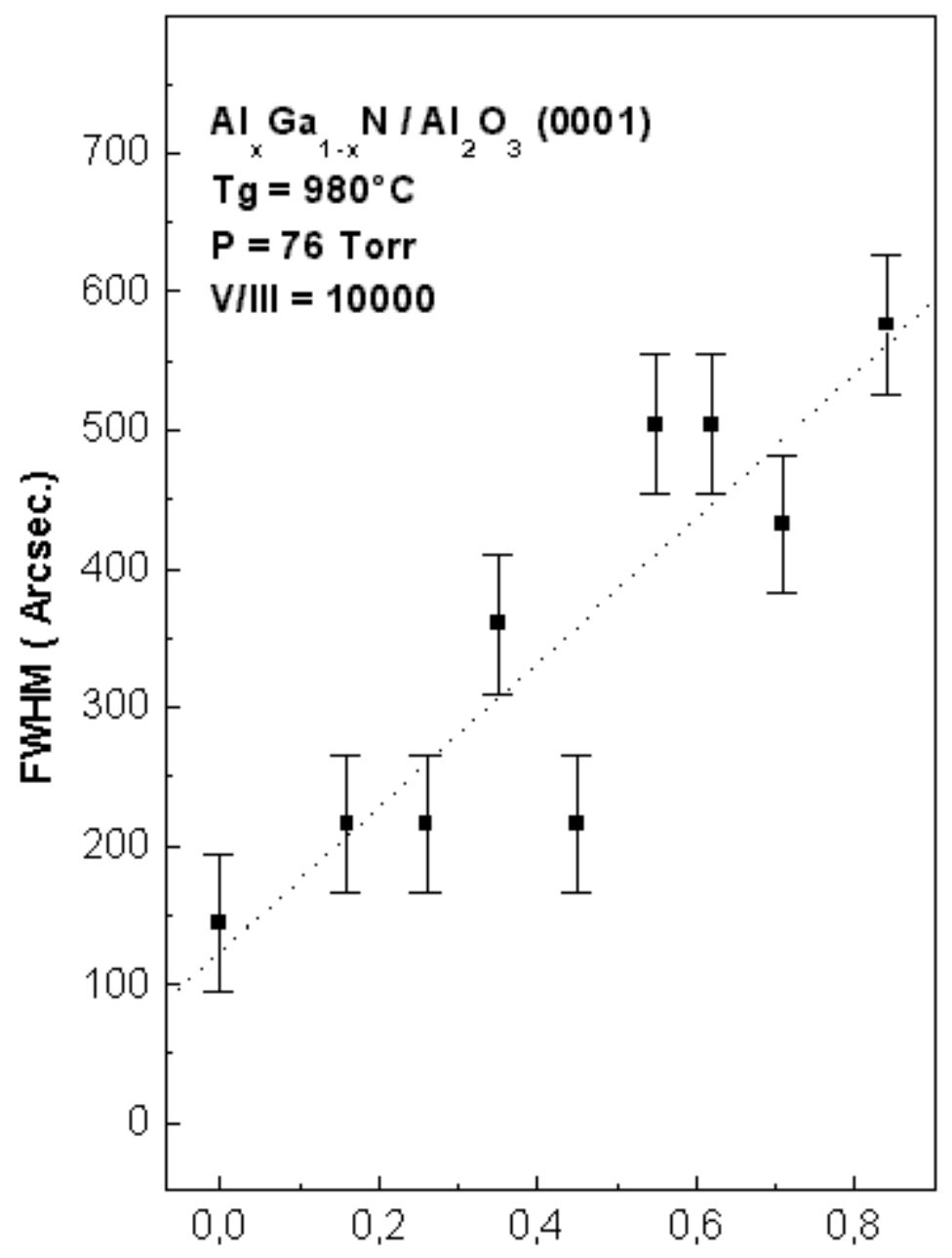

Figure 2. Full width at half maximum in the whole range of $\mathrm{AIGaN}$ composition

Al solid phase composition of $\mathrm{Al}_{x} \mathrm{Ga}_{1-x} \mathrm{~N}$ 


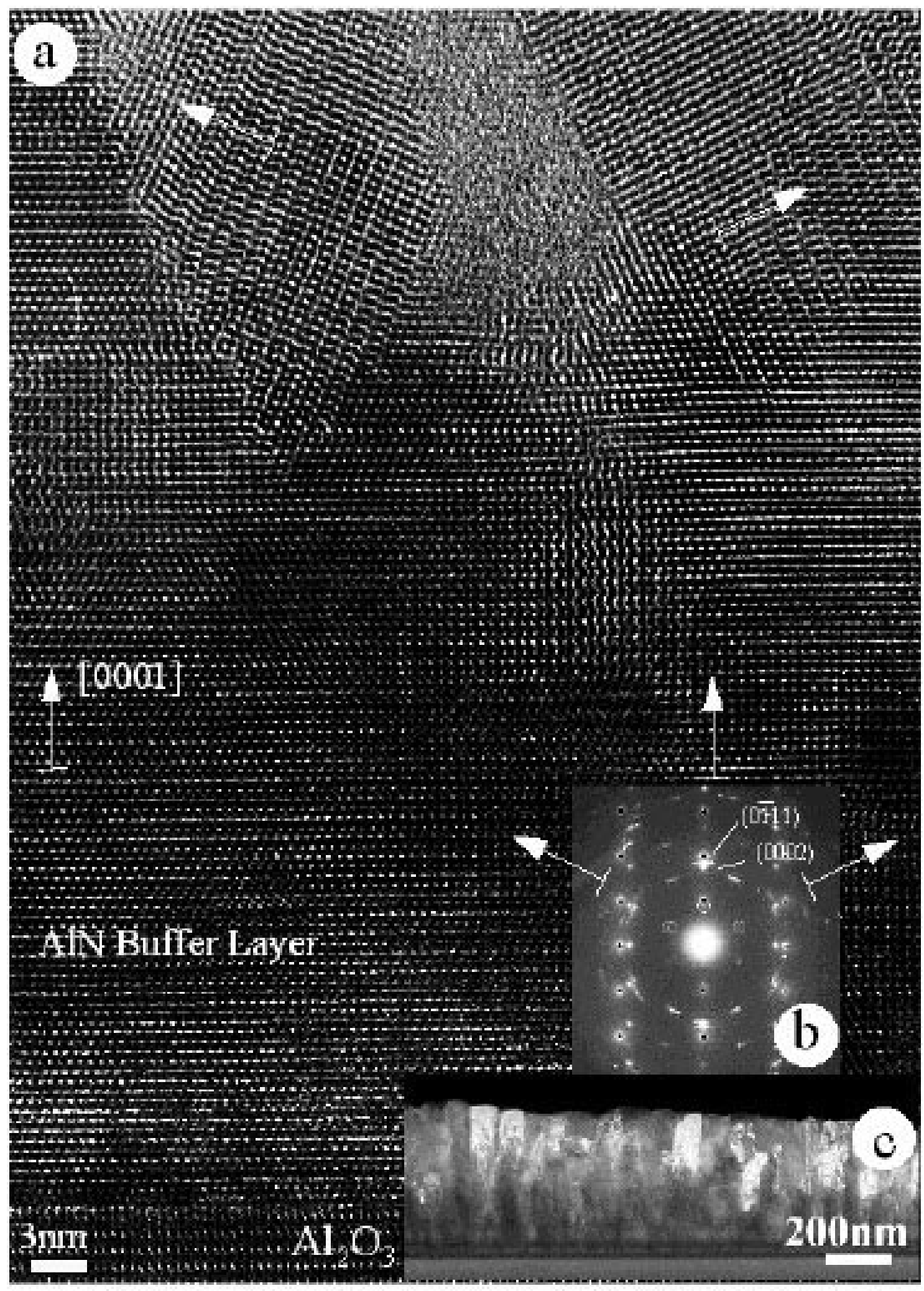

Figure 3. Transmission Electron Microscopy of an $\mathrm{Al}_{0.85} \mathrm{Ga}_{0.15} \mathrm{~N}$ sample: a) High-resolution image, b) Electron diffraction and $\mathrm{c}$ ) low resolution image showing the grains shapes.

(C) 1997 The Materials Research Society

\begin{tabular}{|l|l|l|l|l|}
\hline $\mathrm{M}$ & $\mathrm{R}$ & $\mathrm{S}$ & Internet Journal of & Nitride Semiconductor Research \\
\hline
\end{tabular}

